\title{
Living Kidney Donation in Germany - A Topical Overview
}

\section{Weigand $K^{*}$, Mühlstädt S, Mohammed N, Schaarschmidt T, Fornara P and Kawan F}

University Hospital and Policlinic for Urology of the Medical Faculty, Martin-Luther-University Halle-Wittenberg, Halle/S., Germany

\begin{abstract}
In 2014, a total of 2128 kidney transplants were performed in 40 centers. Of these, 620 were living kidney transplants, which corresponds to around $30 \%$ of all kidney transplants. As the number of postmortem donors has been declining, living donation is becoming more and more important when discussing kidney transplants.

In the following paper, both the obvious advantages for patients, as well as legal principles are to be discussed, so as to emphasize the importance of living kidney transplants against the background of current problems in transplantation medicine in Germany.
\end{abstract}

The age of kidney transplants in humans began with a living kidney donation between identical twins by Murray et al. After introducing medicinal immunosuppression and constantly improving available substance groups, postmortem transplants became more common in the time following.

Nevertheless, the importance of living donations is currently rising rapidly, as it is superior to postmortem transplantation and the number of organ donors has decreased dramatically since the allocation scandal in Germany in 2012.

Keywords: Kidney replacement; Germany; Postmortem; Donation

\section{Why Living Donor Transplantation?}

The answer to this frequently asked question is a better result after the transplantation, as living kidney recipients' graft have a proven better function and longer graft survival rates with lowered morbidity and mortality in comparison to postmortem donations or the obligation to have dialysis (Figure 1-4) [1,2].

The main problem for all patients with kidney replacement therapy, is the increase in morbidity and mortality, the longer the duration of dialysis runs [3]. Currently, the waiting period for an organ offer in Germany, depending on the blood type, takes between 5 to 10 years in the Eurotransplant kidney allocation system (ETKAS).

As a living transplantation can be realized quite soon after dialysis has begun, or even preemptively, recipients are frequently less affected by co-morbidity caused by dialysis. The cold ischemia period [4], thereby balancing the disadvantage of often less suitable HLA-compatibility in comparison to postmortem transplants [5].

This leads to the inherent question, whether a living donation is possible with every patient. On principle, the answer is "yes", as long as a suitable donor is available and the recipient is transplantable. The exact criteria for this are defined in the transplantation law in Germany.

\section{Legal and Social Aspects}

The basis for transplantation medicine in Germany is formed by the transplantation law (TPG) [6]. The TPG entered into force on December $1^{\text {st }}, 1997$ and was amended on August $1^{\text {st }}$, 2012. In the TPG, the three underlying pillars of transplantation medicine, organ harvesting, organ allocation and transplantation are separated from each other to avoid conflicts of interest of involved parties, to protect organ donor and recipient, and to guarantee independence. To separate these areas, the German Foundation for Organ Transplants (DSO) was commissioned to coordinate and implement postmortem organ harvesting. The foundation Eurotransplant (ET) acts as an organ agency. The actual transplantation lies within the center's responsibility [7]. Furthermore, the TPG defines conditions

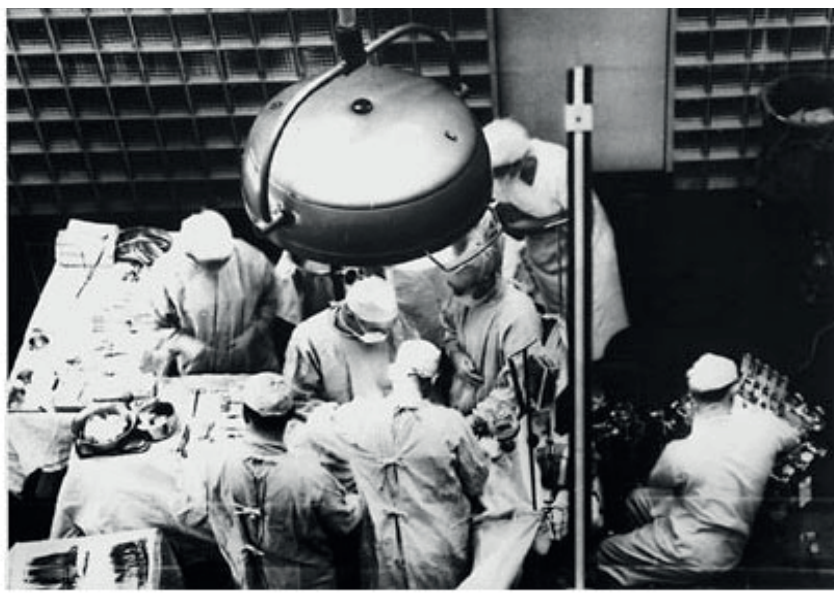

Figure 1: Source Brigham and women's hospital archives, first kidney transplant 1954

and limitations for living donations, as well as legal and ethical principles [8]. According to $\$ 16$ section 1 P. 1 Nos. 2 and 5 TPG, all centers are required to make these decisions in interdisciplinary organ specific conferences. The commission's structure is stipulated in the TPG [9]. The interdisciplinary transplantation conference's members are responsible for all reports and decisions relevant for

${ }^{*}$ Corresponding author: Dr. Karl Weigand, University Hospital and Policlinic for Urology of the Medical Faculty, Martin-Luther-University Halle-Wittenberg Halle/S., Germany, Tel: 0345/5574246; E-mail: karl.weigand@uk-halle.de

Received: November 20, 2015; Accepted: February 28, 2016; Published: February 29, 2016

Citation: Weigand K, Mühlstädt S, Mohammed N, Schaarschmidt T, Fornara P, et al. (2016) Living Kidney Donation in Germany - A Topical Overview. J Kidney 2: 117. doi:10.4172/2472-1220.1000117

Copyright: (c) 2016 Weigand K, et al. This is an open-access article distributed under the terms of the Creative Commons Attribution License, which permits unrestricted use, distribution, and reproduction in any medium, provided the original author and source are credited. 


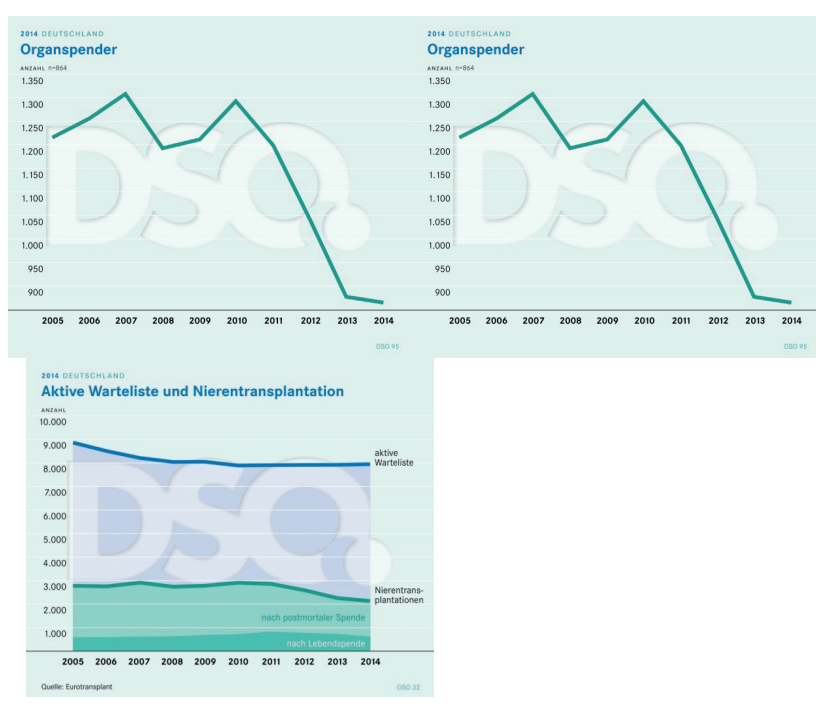

Figure 2: Source DSO Annual report 2014. Left: Organ donation development in Germany; Right: Active waiting list and kidney transplants' development in Germany.

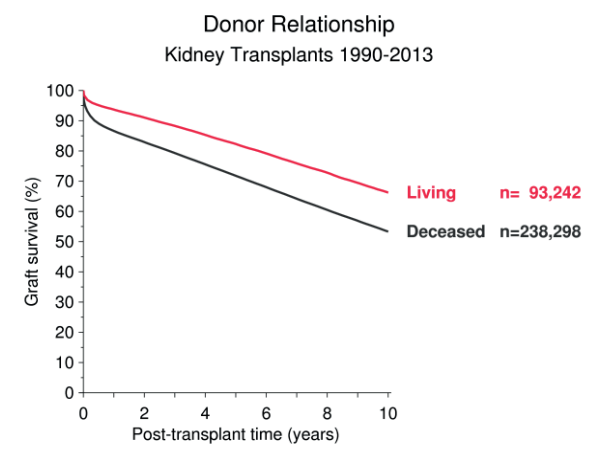

CTS Collaborative Transplant Study

K-15001-0215

Figure 3: CTS, Comparison of transplant survival living donation vs postmortem donation.

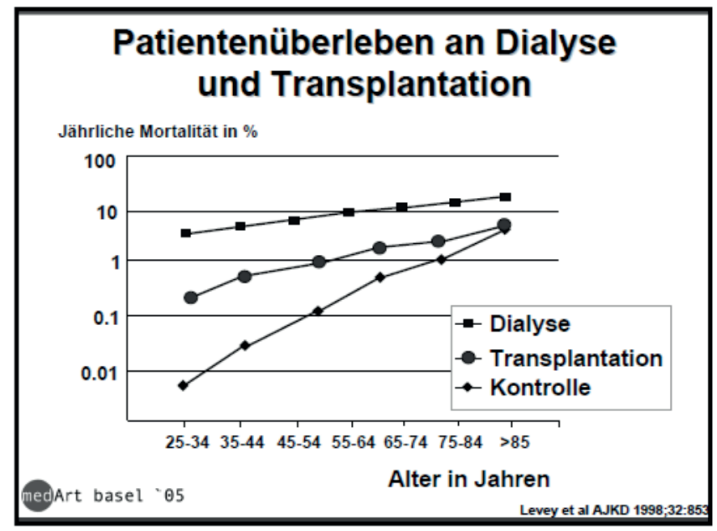

Figure 4: Patient survival with dialysis and after transplantation [14]. allocations.

Changes have been made in the social security code $\mathrm{V} \$ \$ 8$ and 8a (SGB V) to provide for a claim to services in hospital treatment, so that living donors are entitled to complete continued payment of remuneration for a living donation. Additionally, the amendment also affects changes to the social security code VII (SGB VII) which state that any health damage caused by organ donation is to be regarded as an insurance case [10].

\section{The Subsidiarity Principle}

To protect organ donors, the subsidiarity principle, which is determined in the transplantation law, is effective in Germany. It states that to protect the donor, postmortem organ donation is to be preferred, as long as a postmortem organ offer is available at the time of transplantation.

\section{Conditions for a Living Donation}

The legal basis for a living donation in Germany is a relationship or close personal connection between donor and recipient. The donor must be of age and capable of agreeing. The TPG also regulates that continuous medical postoperative care must be guaranteed for donor and recipient ( $\$ 8$ TPG). Furthermore, both patients must be extensively and explicity informed about insurance-legal aspects, as well as acute and chronic health and psychosocial risks [10]. The Amsterdam Forum's recommendations on preparing living donations are used most frequently when preparing a living donation (Tables 1 and 2), [11]. As with any transplantation the blood types must match or be compatible, although the option of ABO-incompatible transplantations exists [12]. Parallel to the medical preparations, there must be an investigation into the donor's psychosocial situation (Table 3). This is to ensure that the donor is absolutely conscious of the consequences of a donation in each and every aspect. Furthermore, the commission examines the personal relationship to the recipient to exclude any possible commercial reasons for a donation.

Finally, the local ethics commission's vote ensures the donor's willingness to volunteer and excludes any form of accepting advantage or organ trafficking ( $\$ 8$ Section 3 P. 2 TPG or state law).

\section{Different Modes of Living Donation}

In Germany, according to the TPG, it is possible to have living donations between relatives or people who are very close to each other. Nevertheless, there are other options besides this traditional form, which are to be explained here briefly.

\section{Cross over donation}

In this case, a living donation between emotionally close persons is impossible due to medical reasons, so that donors could swap with a corresponding couple, as long as there are no medical reasons against such a procedure. This cross over living donation is subject to approval by the respective medical association, as the strong emotional connection as demanded by the TPG does not exist. This procedure is hardly ever used in Germany. Only in few cases has it been performed in two centers. There is no federal database.

\section{Altruistic donation}

This means that a person donates an organ into a pool voluntarily and without financial advantage. This mode is prohibited in Germany.

\section{Commercial donation}

To protect donors, this mode is prohibited in Germany. 


\section{Amsterdam Forum}

Donor's acceptable kidney function

A GFR $<80 \mathrm{ml} / \mathrm{min}$ or $2 \mathrm{SD}$ below average excludes a donation.

Arterial hypertension

Patients with bloodpressure $>140 / 90 \mathrm{mmHg}$ are not suitable as donors

Donors with arterial hypertension should have regular medical follow-up checks

Overweight

Patients with a BMI > 35 should not donate an organ

Lipid metabolism disorders

Are a risk factor but do not exclude a kidney donation.

Diabetes mellitus

Persons known to suffer from diabetes mellitus, a fasting blood sugar > $120 \mathrm{mg} \%$ at least at 2 different times, or blood sugar of $200 \mathrm{mg} \%$ after 2 hours in OGTT should not donate.

Malignity

Melanoma, testicular carcinoma, renal cell carcinoma, Choriocarzinoma, hematological malignant tumor, bronchial carcinoma, breast carcinoma, monoclonal

gammopathy exclude a kidney donation.

A kidney donation is possible with tumor anamnesis if said tumor is curable and cannot be transferred to the recipient.

HLA-compatability

A limitation of a kidney donation due to missing HLA compatability does not seem justified in the light of current data.

Cardiovascular risk

High (Contraindication): unstable coronar syndrome, decompensated myocardium insufficiency, significant arrhythmia, grevious cardiac defects

Moderate (Contraindications): mild angina pectoris, state after myocardial infarction, compensated cardiac degeneration, diabetes mellitus

Mild (individual decision): higher age, ECG-changes, Non-Sinus rhythm, low cardiac capacity, anamnestic cerebral insult, uncontrolled arterial hypertension

Pulmonary function

A higher postoperative risk exists at FEV $1<70 \%$ (predicted) or at a ratio FEV1/FVC $<65 \%$.

Table 1: The Amsterdam Forum's recommendations on selecting suitable live donors [2]

\section{Contraindication for a living donation}

Proteinuria $>300 \mathrm{mg} /$ day

Difficult to adjust hypertension

Psychic illness, drug dependence

Diabetes mellitus, impaired glucose tolerance

Pregnancy

Tumor disease

Age $<18$ years

HIV-infection or other florid infections

$\mathrm{BMI}>35 \mathrm{~kg} / \mathrm{m} 2$

Preexisting condition of the recipient (strict indication): thrombotic micro

angiopathy (HUS/TTP), FSGS, IGA-Nephropathy

Psychosocial problems that sustainably influence the longterm process of donor/ recipient

Table 2: Contraindication for living donation according to the Amsterdam Forum's recommendations [2].

\section{Psychosocial anamnesis/diagnostics'}

Sociodemographic anamnesis and current state

Cognitive capacity

Psychological state

Relation to recipient

Motivation

Knowledge, understanding and preparation of and for the donation

Social support

Financial status, insurance-legal questions

Table 3: Psychosocial evaluation for living kidney donations.

\section{Choice of Side for a Donor Nephrectomy}

When deciding on a side for a donor kidney there are fixed principles to protect the donor. It should always be targeted that the kidney with the lower function be removed. Measuring irregularities of $\pm 5 \%$ must be taken into consideration when using simple kidney sequence scintigraphy [13]. Besides the individual sides' function, vascular supply is especially important when choosing a side. The available diagnostic imaging procedures are selective angiography,
angio-CAT or angio-MRI scans with 3D reconstruction of the arterial vascular supply. Kidneys with single stem vessels should be preferred. In contrast if there is an arterial multiple supply, the side should be chosen individually.

\section{Surgical Techniques of Donor Nephrectomy}

Any surgeon is subject to highest demands when performing a donor nephrectomy, as a healthy organ is being removed and the procedure therefore poses a potentially unneccessary operation. There is no defined standard procedure for harvesting a donor kidney. Regardless of the technique, the donor's highest safety has the utmost priority [14]. Therefore the respective center's established operating method should be used. The warm ischemia period has a direct impact on the transplant's function and should be kept as short as possible. It is clearly recommended to use minimal invasive procedures (Figure 5) to expose the donor to as little stress as possible [4,7,15-17].

\section{Pre- and Postoperative Care after a Living Donation}

Until the TPG's amendment only outpatients' special medical care was regulated in Germany. After realizing that approx. $10 \%$ of all kidney transplants are lost because of insufficient or even missing postoperative care, special medical care before and after a transplantation, especially for living donation recipients, has been added to TPG'S amendment ( $\$$ 116 b TPG).

\section{Conclusion}

Living kidney donations are now a safe and established procedure for kidney transplants and offer proven advantages against postmortem organ donations in regards to the grafts' function and survival. The laparoscopic donor nephrectomy is an especially gentle and attractive option for the donor [7]. The predictability which allows for an optimal preparation of donor and recipient, enables as a whole, optimal conditions for the procedure. In the light of decreasing postmortem donor numbers and the still existing shortage of organs, living kidney donations are the best and 
Citation: Weigand K, Mühlstädt S, Mohammed N, Schaarschmidt T, Fornara P, et al. (2016) Living Kidney Donation in Germany - A Topical Overview. J Kidney 2: 117. doi:10.4172/2472-1220.1000117
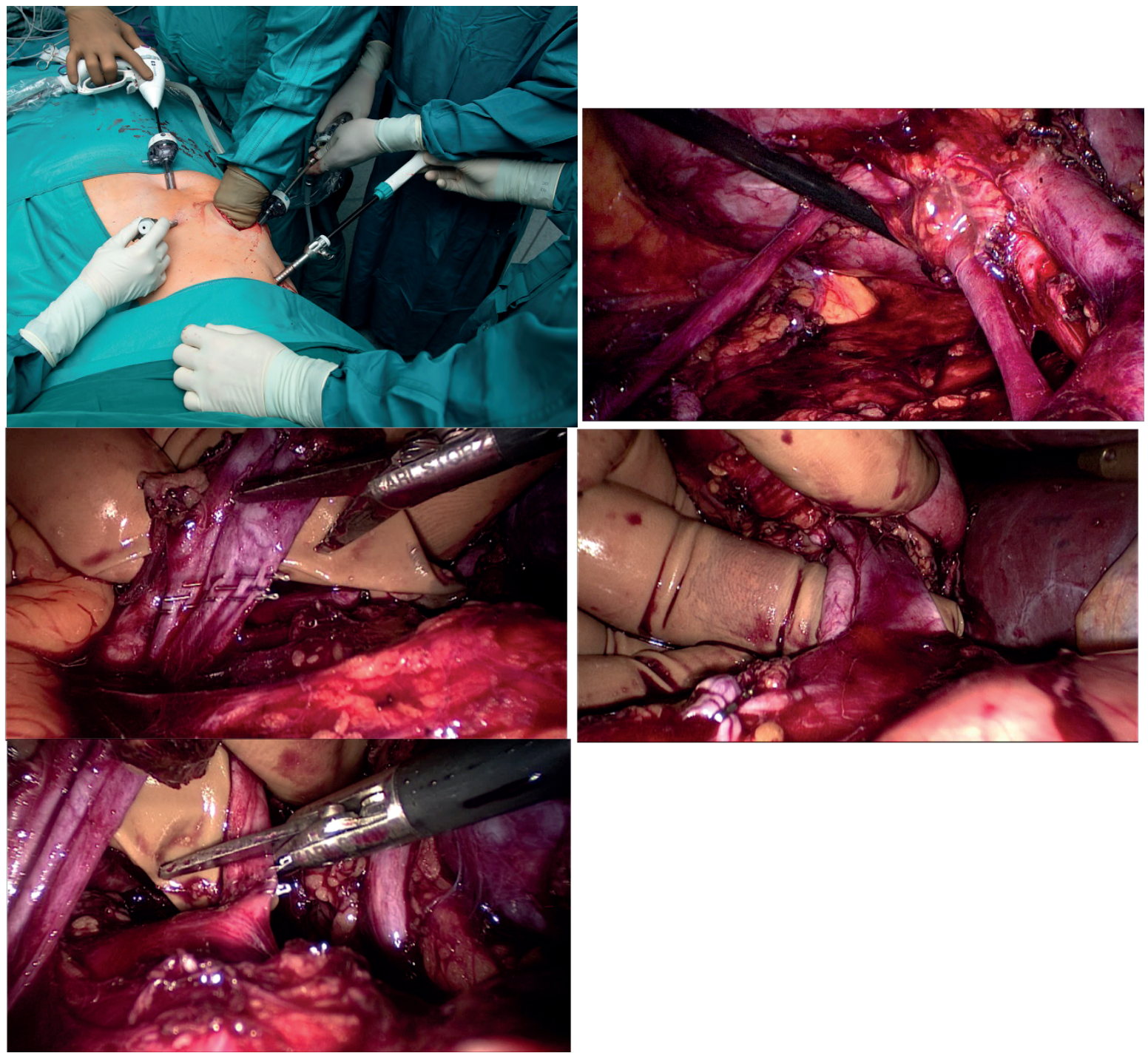

Figure 5: Laparoscopic donor nephrectomy with manually assisted harvesting; 5a: Hand insertion to harvest the kidney via a mini laparotomy; 5b: Fully primed kidney hilus; 5c: Digital probing of splenic vessels; $5 \mathrm{~d}$, e: Removal of the renal artery (d) and renal vein (e) after occlusion with an endostapler.

safest mode of transplantation. It is possible to improve acceptance - especially the donors' - by using minimally invasive procedures.

\section{References}

1. Deutsche Stiftunng Organtransplantation (2015) DSO Jahresbericht 2014.

2. Levey AS, Beto JA, Coronado BE (1998) Controlling the epidemic of cardiovascular disease in chronic renal disease: what do we know? What do we need to learn? Where do we go from here? National Kidney Foundation Task force on Cardivascular Disease. Am J Kidney Dis 32: 853-906.

3. Thamer M, Hwang W, Fink NE (2000) US nephrologists' recommendation of dialysis modality: results of a national survey. Am J Kidney Dis 36: 1155-1165.

4. Hoda MR, Greco F, Reichelt O (2010) Right-sided transperitoneal handassisted laparoscopic donor nephrectomy: is there an issue with the renal vessels? J Endourol 24: 1947-1952.

5. Opelz G (1997) Impact of HLA compatibility on survival of kidney transplants from unrelated live donors. Transplantation 64: 1473-1475.

6. (2013) Transplantationsgesetz (TPG) in der Fassung der Bekanntmachung vom 04.09.2007 (BGBI. I S. 2206) geändert durch Gesetz vom 15.07.2013 (BGBI. I S. 2423) m.W.v.
7. Fornara P, Hamza A, Weigand K (2014) Nierentransplantation. Urologie

8. Bundesärztekammer (2013) Richtlinien zur Organtransplantation gem. § 16 Abs. 1 S. 1 Nrn. 2 u. 5 TPG Dtsch Arztebl 110: A-241 / B-225 / C-225.

9. Loer M (2015) Medizinische, ethische und rechtliche Grenzen der Strafbarkeit bei Alllokationsverstößen in der Transplantationsmedizin, Masterarbeit Universitätsbibliothek Martinn-Luther-Universität Halle, in Druck.

10. Lutz J, Heemann U (2009) Spendervorbereitung für die Nierenlebendspende. Nephrologe 4: 213-220.

11. Delmonico F (2005) A Report of the Amsterdam Forum On the Care of the Live Kidney Donor: Data and Medical Guidelines. Transplantation 79: 53-66.

12. Riediger C (2010) Therapeutische Apherese vor ABO-inkompatibler Lebendspende der Niere. Transplantationsmedizin p: S273.

13. Müller-Suur R, Durand E (2003) Nierenfunktionsbestimmungen mit Clearance: Methoden und Indikationen. Nuklearmediziner 26: 181-188

14. Kasiske BL, Ravenscraft M, Ramos EL (1996) The evaluation of living rena transplant donors: clinical practice guidelines. Ad Hoc Clinical Practice Guidelines Subcommittee of the Patient Care and Education Committee of the American Society of Transplant Physicians. J Am Soc Nephrol 7: 2288-2313.

15. Fornara P, Doehn C, Seyfarth M (2000) Why is urological laparoscopy minimally 
Citation: Weigand K, Mühlstädt S, Mohammed N, Schaarschmidt T, Fornara P, et al. (2016) Living Kidney Donation in Germany - A Topical Overview. J Kidney 2: 117. doi:10.4172/2472-1220.1000117

Page 5 of 5

invasive? Eur Urol 37: 241-250.

16. Greco F, Hoda MR, Alcaraz A (2010) Laparoscopic living-donor nephrectomy: analysis of the existing literature. Eur Urol 58: 498-509.
17. Hoda MR, Hamza A, Wagner S (2010) Impact of hand-assisted laparoscopic living donor nephrectomy on donor's quality of life, emotional, and social state. Transplant Proc 42: 1487-1491. 